\title{
Preliminary Performance of the Advanced Dental Admission Test (ADAT): Association Between ADAT Scores and Other Variables for Applicants to Residency Programs at a U.S. Dental School
}

\begin{abstract}
Lindsay L. DeSantis, Ahmed Ghoneima, Vanchit John, George Eckert, Kelton T. Stewart
Abstract: Historically, dental residency programs have used numerical assessment criteria to evaluate and identify qualified candidates for admission. Recent elimination of such assessment tools has undermined many programs' holistic evaluation process. The Advanced Dental Admission Test (ADAT) was developed and recently piloted in hopes of addressing this issue. The aim of this study was to evaluate the preliminary performance and validity of the ADAT by exploring the association between ADAT scores and other variables for a sample of applicants to residency programs. The WebAdMIT admissions database was used to identify the test scores and educational and demographic information of 92 individuals who completed the pilot ADAT and were seeking a 2017 postgraduate specialty position at Indiana University School of Dentistry. The results showed that the ADAT had strong to weak correlations with certain applicant variables $(\mathrm{p}<0.05)$. No significant differences were found for age, race, school location, or country of origin. However, males performed better than females $(p<0.05)$, and non-Hispanics performed better than Hispanics $(\mathrm{p}<0.01)$. ADAT component scores were also higher for individuals with a history of research activity $(\mathrm{p}<0.05)$. This study found that significant associations existed between the ADAT and indices typically associated with competitive applicants. These findings suggest that the ADAT may serve as a useful numerical assessment instrument, with the potential to identify highperforming candidates. Furthermore, the ADAT seemed to be a plausible option for programs seeking to incorporate a quantitative assessment instrument as part of a holistic candidate selection process.
\end{abstract}

Lindsay L. DeSantis, DDS, MS, is a practicing orthodontist and a graduate of the Department of Orthodontics and Oral Facial Genetics, Indiana University School of Dentistry; Ahmed Ghoneima, BDS, MSc, PhD, is Associate Professor and Chair, Orthodontic Department, Hamdan Bin Mohammed College of Dental Medicine, Mohammed Bin Rashid University of Medicine and Health Sciences; Vanchit John, BDS, MDS, DDS, MSD, is Associate Professor and Chair, Department of Periodontics and Allied Dental Programs, Indiana University School of Dentistry; George Eckert, MAS, is Biostatistician Supervisor, Department of Biostatistics, Indiana University School of Medicine; and Kelton T. Stewart, DDS, MS, is Associate Professor and Interim Chair and Graduate Program Director, Department of Orthodontics and Oral Facial Genetics, Indiana University School of Dentistry. Direct correspondence to Dr. Kelton Stewart, Indiana University School of Dentistry, Department of Orthodontics and Oral Facial Genetics, 1121 West Michigan Street, Room 206, Indianapolis, IN 46202; 317-278-1087; keltstew@iu.edu.

Keywords: advanced dental education, postgraduate education, Advanced Dental Admission Test (ADAT), educational measurement, admissions

Submitted for publication 3/3/18; accepted 5/19/18

doi: 10.21815/JDE.018.137

$\mathrm{D}$ ental residency programs aim to identify and select applicants who possess the knowledge and personal attributes that will allow them to be successful in the pursuit of advanced dental education training. ${ }^{1}$ The number of positions available in graduate training programs are limited, and programs seek the most qualified individuals from a growing pool of competitive applicants. American Dental Association (ADA) survey results found that, since
2004 , there has been a $10 \%$ increase in the number of individuals applying for dental residency programs. ${ }^{2}$ While there are slight variations among specialty programs, on average there are 15 applicants for every open position. ${ }^{1}$ Therefore, the means by which applicants are assessed have become even more important in the selection process. Historically, dental residency programs have relied on numerous criteria such as an applicant's grades, class rank, National Board 
Dental Examination (NBDE) scores, and letters of recommendation to determine which candidates will receive an interview. ${ }^{3}$ However, significant changes have occurred in dental education over the past few years that have resulted in the elimination of many quantitative indicators formerly used by programs to identify well-qualified applicants for acceptance into residency programs.

For many years, one of the measures most frequently used by residency programs to evaluate applicants was the NBDE. Since dental schools' grading criteria vary, making GPA difficult to use as a comparative measure, graduate residency programs often used NBDE scores to distinguish the academic abilities of applicants from schools across the nation. A survey of pediatric dentistry program directors published in 2009 reported that NBDE scores were the most important criterion for selecting residents, followed by dental school clinical grades, class rank, and GPA. ${ }^{4}$ Furthermore, Fagin et al. reported that program directors ranked the NBDE Part I as one of the most important factors for determining which applicants to interview. ${ }^{5}$ However, in January 2012, the Joint Commission on National Dental Examinations (JCNDE) decided to eliminate the release of numerical scores and report results only on a pass/ fail basis. The JCNDE stated that the NBDE Part I and Part II is designed for use by state dental boards to evaluate whether a candidate for licensure has the "required cognitive skills to safely practice dentistry (minimum competency)." "Neumann and MacNeil argued that the NBDE Part I was "never designed or statistically validated to differentiate students beyond a pass/fail level." ${ }^{\text {"7 }}$ This change was not popular among dental educators, and a 2014 survey found that $70.9 \%$ of responding program directors felt the lack of numerical NBDE Part I scores made it "more difficult" to select applicants for interview. ${ }^{5}$

Along with elimination of NBDE scores, postgraduate dental academia has seen other substantial changes that have impacted the residency applicant assessment process. Even with schools that provide GPA and class ranks, it is somewhat difficult to make direct comparisons among students from different institutions due to differences in curricula and grading practices among schools. ${ }^{8}$ To further compound this issue, a number of dental schools have introduced pass/fail grading. This pass/fail system poses a significant challenge to postgraduate residency programs in their attempt to assess applicants' abilities.

Fagin et al.'s study found that $75.8 \%$ of responding program directors wanted "some standardized, numerically scored exam to aid in the admissions process." ${ }^{\circ}$ The majority of these directors (47.5\%) wanted to have the NBDE Part I scored again, while $15.3 \%$ favored a specialty-specific entrance exam and $13.0 \%$ a common exam for all specialty programs. In an attempt to address this significant concern among postgraduate dental residency programs, the ADA developed the Advanced Dental Admission Test (ADAT). The ADA states that the ADAT is designed for "admission purposes, to help advanced dental education programs identify the most qualified, strongest candidates for selection into advanced dental education programs." 9

The ADAT consists of 200 questions with topics spanning the biomedical sciences, clinical sciences, research interpretation, evidence-based dentistry, and principles of ethics and patient management. ${ }^{9}$ A pilot administration of the ADAT was conducted for the 2016 application cycle, and a total of 460 applicants took the exam. The ADA has released information about the initial performance of the exam and provided preliminary evidence suggesting that the ADAT possesses moderate testing reliability. ${ }^{10}$ To date, however, no studies have been conducted independent of the exam's creators to evaluate the preliminary performance of the ADAT and further validate its usefulness as a numerical admissions assessment tool. Therefore, the aim of this study was to evaluate the preliminary performance and validity of the ADAT by exploring the association between ADAT scores and other variables for a sample of applicants to residency programs.

\section{Methods}

Prior to initiation of the study, formal approval from the Indiana University Institutional Review Board was obtained (IRB\# 1611211013). The sample population consisted of individuals who registered with the American Dental Education Association Postdoctoral Application Support Service (ADEA PASS) for entrance into a 2017 postgraduate specialty position at Indiana University School of Dentistry (IUSD). Subjects were included if they had completed the ADAT pilot exam and applied to an IUSD advanced education program for the 2016-17 application cycle.

A total of 92 individuals were identified and included in the study. We received de-identified data from the IUSD Office of Graduate Education using the WebAdMIT application database. The following 
information was extracted from the provided data. Demographic, educational, and professional data consisted of age at the time of application submission (25-29, 30-34, 35-39, 40 and over); gender (male, female); ethnicity (not Hispanic or Latino, Hispanic or Latino); race (African American, American Indian, Asian, Hawaiian/Pacific Islander, White, other, not disclosed); country of origin; year of dental school graduation; regional location of undergraduate school (Northeast, South, Midwest, West, non-U.S.); regional location of dental school (Northeast, South, Midwest, West, non-U.S.); advanced specialty area of interest (endodontics, dental materials, operative, oral surgery, orthodontics, pedodontics, periodontics, prosthodontics); history of private practice experience after dental school (no, yes); and history of research experience (no, yes). Quantitative data collected were undergraduate GPA; dental school GPA; dental school class rank; GRE scores (verbal, quantitative, and analytical sections); and TOEFL score. The designations for race, ethnicity, and regional school locations followed the categorizations used by the 2010 U.S. Census. All obtained data were managed using RedCap, an online data repository.

Associations of continuous variables with ADAT scores were evaluated using correlation coefficients. One-way ANOVA with software package SAS version 9.4 (SAS Institute Inc., Cary, NC, USA) was used to evaluate associations of categorical variables with ADAT scores. For the analyses, due to small sample sizes, categories were combined for several variables when evaluating the associations with the ADAT scores. Categories that were combined were as follows: endodontics, oral surgery, and prosthodontics for dental specialties; age for any participants 35 and older; African American, American Indian, other, and not disclosed were combined into "Other" for race; and not disclosed was combined with not Hispanic or Latino into "Other" for ethnicity.

A statistical significance level of $5 \%$ was utilized for the study. The following correlation interpretation scheme, devised by Evans in 1996, was employed: 0.0-0.19 was very weak correlation; 0.2-0.39 was weak correlation; $0.4-0.59$ was moderate correlation; $0.6-0.79$ was strong correlation; and 0.8-1.0 was very strong correlation. ${ }^{11}$ The software package used for power calculations was PASS 13 (NCSS, LLC, Kaysville, UT, USA). The study had $80 \%$ power to detect correlations of 0.29 for ADAT vs. undergraduate GPA, 0.30 for ADAT vs. dental school GPA, 0.33 for ADAT vs. dental school class rank, and 0.40 for ADAT vs. GRE score.

\section{Results}

A total of 92 applicants to IUSD postgraduate programs completed the ADAT in the study year. This number corresponded to approximately $20 \%$ of the total individuals who completed the 2016 ADAT pilot exam. None of the eight IUSD postgraduate programs required the ADAT for the 2016 cycle. There were no statistically significant differences in mean ADAT score across the different specialties. The majority of applicants seeking admission into an IUSD postgraduate program applied for pediatric dentistry or orthodontic positions (84\%).

Among the applicants, $77 \%$ were between the ages of 25 and 29 ; only $9 \%$ were over the age of 35 (Table 1). The sample consisted of roughly equal numbers of male and female applicants. Most applicants identified themselves as not Hispanic/Latino (88\%). Whites $(67 \%)$ constituted the largest identified racial group, followed by Asians (23\%). Over three-quarters of the applicants were U.S. citizens, with approximately $60 \%$ attending dental school in the Midwest or South. The majority of applicants reported having no private practice experience $(75 \%)$. However, $80 \%$ reported they had some involvement with research while in dental school.

Descriptive statistics for all academic variables are shown in Table 2. Regarding performance on the ADAT, the mean total ADAT score for the applicants was 522 (SD 68), with minimum and maximum scores of 300 and 700, respectively. Applicants' performance was similar on all four of the ADAT subscales, ranging from 520 (SD 92) on the clinical sciences section to 528 (SD 92) on the biomedical sciences section. The scores for the principles of ethics and patient management section were recalled by the ADA prior to the completion of data collection and were not included in the assessment of the exam.

The ADAT total score showed a strong correlation with dental school GPA $(r=0.64, \mathrm{p}<0.0001)$ and dental school class rank $(r=0.60, p<0.0001)$. Moderate correlations were found between the total ADAT score and the quantitative $(\mathrm{r}=0.58, \mathrm{p}<0.0001)$ and verbal sections ( $r=0.44, p=0.0022)$ of the GRE (Table 3 ). In further analyzing the ADAT's components, we found moderate correlations with the GRE quantitative score and every section of the ADAT, with the exception of the data, research interpretation, and evidence-based dentistry section, which showed a strong correlation. Moderate correlations were also seen with dental school GPA and every section of 


\begin{tabular}{|c|c|c|}
\hline Variable & Response & Number (\%) \\
\hline Dental specialty & $\begin{array}{l}\text { Orthodontics } \\
\text { Pedodontics } \\
\text { Endodontics } \\
\text { Oral surgery } \\
\text { Prosthodontics }\end{array}$ & $\begin{array}{c}41(45 \%) \\
36(39 \%) \\
9(10 \%) \\
4(4 \%) \\
2(2 \%)\end{array}$ \\
\hline Age in years & $\begin{array}{l}25-29 \\
30-34 \\
35-39 \\
40 \text { and over }\end{array}$ & $\begin{array}{c}71(77 \%) \\
13(14 \%) \\
6(7 \%) \\
2(2 \%)\end{array}$ \\
\hline Gender & $\begin{array}{l}\text { Male } \\
\text { Female } \\
\text { Not disclosed }\end{array}$ & $\begin{array}{c}44(48 \%) \\
46(50 \%) \\
2(2 \%)\end{array}$ \\
\hline Ethnicity & $\begin{array}{l}\text { Not Hispanic or Latino } \\
\text { Hispanic or Latino } \\
\text { Not disclosed }\end{array}$ & $\begin{array}{l}81(88 \%) \\
6(7 \%) \\
5(5 \%)\end{array}$ \\
\hline Race & $\begin{array}{l}\text { African American } \\
\text { American Indian } \\
\text { Asian } \\
\text { White } \\
\text { Other } \\
\text { Not disclosed }\end{array}$ & $\begin{aligned} & (1 \%) \\
1 & (1 \%) \\
21 & (23 \%) \\
62 & (67 \%) \\
1 & (1 \%) \\
6 & (7 \%)\end{aligned}$ \\
\hline Citizenship & $\begin{array}{l}\text { Non-U.S. } \\
\text { U.S. }\end{array}$ & $\begin{array}{l}14(15 \%) \\
78(85 \%)\end{array}$ \\
\hline Undergraduate location & $\begin{array}{l}\text { Non-U.S. } \\
\text { West } \\
\text { Midwest } \\
\text { Northeast } \\
\text { South }\end{array}$ & $\begin{array}{c}16(17 \%) \\
15(16 \%) \\
27(29 \%) \\
6(7 \%) \\
28(30 \%)\end{array}$ \\
\hline Dental school location & $\begin{array}{l}\text { Non-U.S. } \\
\text { West } \\
\text { Midwest } \\
\text { Northeast } \\
\text { South }\end{array}$ & $\begin{array}{c}14(15 \%) \\
7(8 \%) \\
30(33 \%) \\
11(12 \%) \\
30(33 \%)\end{array}$ \\
\hline Private practice experience & $\begin{array}{l}\text { No } \\
\text { Yes }\end{array}$ & $\begin{array}{l}69(75 \%) \\
23(25 \%)\end{array}$ \\
\hline Research experience & $\begin{array}{l}\text { No } \\
\text { Yes }\end{array}$ & $\begin{array}{l}18(20 \%) \\
74(80 \%)\end{array}$ \\
\hline
\end{tabular}

the ADAT, with the exception of the critical thinking section, which had a strong correlation. Moderate correlations existed between dental school class rank and the biomedical sciences and critical thinking sections. Undergraduate GPA had a weak correlation with all sections of the ADAT. Lastly, the TOEFL exam showed a moderate to strong correlation with every section of the ADAT, except for the biomedical sciences section, where it had a very weak correlation. However, these TOEFL exam correlations were not statistically significant.
When correlating ADAT total scores with demographic variables, we found no significant differences for age, race, school location, or country of origin. However, male applicants scored significantly higher than female applicants on the ADAT total score $(\mathrm{p}=0.0101)$, as well as on the biomedical sciences $(\mathrm{p}=0.0154)$, critical thinking $(\mathrm{p}=0.0073)$, and data, research interpretation, and evidence-based dentistry ( $<<0.0001$ ) subscales (Table 4$)$. Additionally, non-Hispanic/Latinos scored significantly higher on the ADAT total score $(\mathrm{p}=0.0067)$, critical thinking $(\mathrm{p}=0.0094)$, and data, research interpretation, and evidence-based dentistry $(\mathrm{p}=0.0104)$ subscale scores (Table 5). Individuals who had a history of research experience scored higher on every section of the ADAT. The differences between students with and without research experience were statistically significant for the ADAT total score $(\mathrm{p}=0.0120)$ and two of the subscales: biomedical sciences $(\mathrm{p}=0.0004)$ and critical thinking $(\mathrm{p}=0.0049)$ (Table 6).

\section{Discussion}

While the holistic assessment of an applicant is the best way to determine qualified applicants, a key component of the assessment process has historically been numerical metrics. Three of the most common numerical metrics are dental school GPA, class rank, and GRE scores. The results of our study showed that significant correlations existed between the ADAT and these commonly used metrics. Not only do our findings contribute to acceptance of the exam's preliminary performance in reflecting applicants' academic abilities, they also help demonstrate the test's external validity. According to Cooper, external validity, which is necessary for evaluating construct validity of an exam, places the focus on a test score's association with additional variables, including "measures of the same construct and measures of different constructs." 12 These associations provide information regarding "whether the test measures the construct it is intended to measure and begins to examine the appropriateness of test score interpretations." In our study, these correlations contributed to the broad goal of assessing the construct validity of this test.

While the correlations with the TOEFL exam were not statistically significant due to the limited number of applicants who took that exam, further research with a larger sample size may demonstrate a statistically significant correlation between these 
Table 2. Quantitative measures provided by applicants in support of their application ( $\mathrm{N}=92)$

\begin{tabular}{lcccc} 
Measure & N & Mean (SD) & Min & Max \\
\hline TOEFL score & 10 & $102.5(8.3)$ & 91 & 116 \\
GRE quantitative & 45 & $157.3(6.1)$ & 142 & 170 \\
GRE verbal & 45 & $155.3(8.7)$ & 130 & 170 \\
GRE analytical & 45 & $4.03(1.04)$ & 0 & 6 \\
Undergrad GPA & 92 & $3.57(0.30)$ & 1.94 & 4 \\
Dental school GPA & 84 & $3.55(0.35)$ & 1.94 & 3.98 \\
Dental school class rank & 67 & $29.8(24.2)$ & 91 & 1 \\
ADAT biomedical sciences & 92 & $528(92)$ & 260 & 790 \\
ADAT clinical sciences & 92 & $520(92)$ & 220 & 750 \\
ADAT critical thinking & 92 & $524(71)$ & 300 & 720 \\
ADAT data, research interpretation, and evidence-based dentistry & 92 & $522(97)$ & 280 & 800 \\
ADAT total score & 92 & $522(68)$ & 300 & 700
\end{tabular}

Table 3. Correlations of applicants' TOEFL, GRE, GPA, and class rank with ADAT scores

\begin{tabular}{|c|c|c|c|c|}
\hline ADAT & Variable & $\mathrm{N}$ & Correlation & p-value \\
\hline \multirow[t]{7}{*}{ Biomedical sciences } & TOEFL score & 10 & 0.17 & 0.6514 \\
\hline & GRE quantitative & 45 & 0.40 & $0.0063^{*}$ \\
\hline & GRE verbal & 45 & 0.11 & 0.4600 \\
\hline & GRE analytical & 45 & 0.17 & 0.2656 \\
\hline & Undergrad GPA & 92 & 0.22 & $0.0345^{*}$ \\
\hline & Dental school GPA & 84 & 0.49 & $<0.0001^{*}$ \\
\hline & Dental school class rank & 67 & 0.57 & $<0.0001^{*}$ \\
\hline \multirow[t]{7}{*}{ Clinical sciences } & TOEFL score & 10 & 0.63 & 0.0504 \\
\hline & GRE quantitative & 45 & 0.47 & $0.0011^{*}$ \\
\hline & GRE verbal & 45 & 0.33 & $0.0286^{*}$ \\
\hline & GRE analytical & 45 & 0.15 & 0.3378 \\
\hline & Undergrad GPA & 92 & 0.36 & $0.0003^{*}$ \\
\hline & Dental school GPA & 84 & 0.48 & $<0.0001^{*}$ \\
\hline & Dental school class rank & 67 & 0.38 & $0.0012 *$ \\
\hline \multirow[t]{7}{*}{ Critical thinking } & TOEFL score & 10 & 0.48 & 0.1646 \\
\hline & GRE quantitative & 45 & 0.59 & $<0.0001^{*}$ \\
\hline & GRE verbal & 45 & 0.36 & 0.0159* \\
\hline & GRE analytical & 45 & 0.26 & 0.0885 \\
\hline & Undergrad GPA & 92 & 0.37 & $0.0003^{*}$ \\
\hline & Dental school GPA & 84 & 0.62 & $<0.0001 *$ \\
\hline & Dental school class rank & 67 & 0.58 & $<0.0001^{*}$ \\
\hline \multirow{7}{*}{$\begin{array}{l}\text { Data, research interpretation, } \\
\text { and evidence-based dentistry }\end{array}$} & TOEFL score & 10 & 0.42 & 0.2397 \\
\hline & GRE quantitative & 45 & 0.66 & $<0.0001^{*}$ \\
\hline & GRE verbal & 45 & 0.64 & $<0.0001^{*}$ \\
\hline & GRE analytical & 45 & 0.42 & 0.0039* \\
\hline & Undergrad GPA & 92 & 0.30 & $0.0032 *$ \\
\hline & Dental school GPA & 84 & 0.44 & $<0.0001^{*}$ \\
\hline & Dental school class rank & 67 & 0.33 & $0.0061^{*}$ \\
\hline \multirow[t]{7}{*}{ Total score } & TOEFL score & 10 & 0.51 & 0.1398 \\
\hline & GRE quantitative & 45 & 0.58 & $<0.0001 *$ \\
\hline & GRE verbal & 45 & 0.44 & $0.0022^{*}$ \\
\hline & GRE analytical & 45 & 0.29 & $0.0499 *$ \\
\hline & Undergrad GPA & 92 & 0.37 & $0.0002 *$ \\
\hline & Dental school GPA & 84 & 0.64 & $<0.0001^{*}$ \\
\hline & Dental school class rank & 67 & 0.60 & $<0.0001^{*}$ \\
\hline
\end{tabular}


Table 4. Applicants' ADAT mean scores (SD) by gender

\begin{tabular}{lccc} 
ADAT Total/Section & Male & Female & p-value \\
\hline ADAT total score & $541(10)$ & $505(9)$ & $0.0101^{*}$ \\
Critical thinking & $545(11)$ & $505(10)$ & $0.0073^{*}$ \\
Biomedical sciences & $552(14)$ & $506(12)$ & $0.0154^{*}$ \\
Clinical sciences & $526(16)$ & $515(11)$ & 0.5602 \\
Data, research interpretation, and evidence-based dentistry & $563(15)$ & $484(12)$ & $<0.0001^{*}$ \\
*Statistically significant & & &
\end{tabular}

Table 5. Applicants' ADAT mean scores (SD) by ethnicity

\begin{tabular}{lccc} 
ADAT Total/Section & Not Hispanic/Latino & Hispanic/Latino & p-value \\
\hline ADAT total score & $527(7)$ & $450(36)$ & $0.0067^{*}$ \\
Critical thinking & $529(7)$ & $452(37)$ & $0.0094^{*}$ \\
Biomedical sciences & $533(10)$ & $458(49)$ & 0.0537 \\
Clinical sciences & $524(10)$ & $457(30)$ & 0.0827 \\
Data, research interpretation, and evidence-based dentistry & $529(10)$ & $425(49)$ & $0.0104^{*}$ \\
*Statistically significant & & & \\
\hline
\end{tabular}

Table 6. Applicants' ADAT mean scores (SD) by presence or lack of research experience

\begin{tabular}{|c|c|c|c|}
\hline ADAT Total/Section & o Research Experience & Research Experience & p-value \\
\hline ADAT total score & $486(18)$ & $531(7)$ & $0.0120^{*}$ \\
\hline Critical thinking & $482(18)$ & $534(8)$ & $0.0049 *$ \\
\hline Biomedical sciences & $461(10)$ & $544(10)$ & $0.0004^{*}$ \\
\hline Clinical sciences & $508(21)$ & $523(11)$ & 0.5535 \\
\hline Data, research interpretation, and evidence-based dentistry & $488(28)$ & $530(10)$ & 0.1006 \\
\hline
\end{tabular}

two assessment instruments. Language proficiency has been considered important in academic performance, and Lucas et al. found that those with a higher proficiency in English attained significantly better grades. ${ }^{13}$ Cho and Bridgeman's study of 2,000 graduate and undergraduate students at ten U.S. universities found a correlation between academic grades and TOEFL scores. ${ }^{14}$ A demonstrated significant association between the ADAT and TOEFL could help expand the utility of the ADAT when evaluating the preparedness of international students for U.S. postgraduate programs.

When evaluating the sample population based on demographics, we found several statistically significant differences in ADAT performance. Male applicants outperformed females on various areas of the exam including the ADAT total score, as well as the biomedical sciences, critical thinking, and data, research interpretation, and evidence-based dentistry sections. We suggest three possible reasons that could explain this gender-based difference. First, a fundamental difference in academic ability could exist between the male and female applicants in this study. Although that may be the most plausible explanation, when the data were evaluated based on gender alone, no significant differences were found for any of our evaluated academic parameters: mean GRE verbal 156/154 (male/female), mean GRE quantitative 158/156, mean GRE analytical 4.1/3.9, undergraduate mean GPA:3.5/3.6, dental mean GPA 3.5/3.6, or mean dental school class rank 31/29.

Second, it is possible that an unintended gender bias exists within the ADAT. When standardized exams are created, they intend to "measure intelligence and general knowledge, but they are normed based on the knowledge and values of majority groups, which can create bias against minority groups, including gender." ${ }^{15}$ Even with the extensive steps 
taken during its construction, it is possible that the ADAT possesses structural or content components that allow males to outperform females. We feel that there is insufficient evidence to confirm or refute this possible elucidation. A final explanation could be the influence of a more widespread societal bias between male and female performance on standardized examinations. Researchers have long acknowledged a significant gender gap in high-stakes testing performances. A study published in 2006 found that males had significantly higher DAT academic averages and PAT scores than females. ${ }^{16}$ More importantly, in that study, males had significantly higher state board clinical scores, including NBDE I and II scores. Many hypotheses have been offered to explain gender performance gaps on high-stakes examinations. Some attribute differences in performance to low self-esteem among females, while other theories include stereotype threat, aversion to risk-taking, test bias, fear of success, test anxiety, and other personal characteristics. ${ }^{17}$ Regardless of the reasoning, many have deliberated as to whether high-stakes exams fail to accurately reflect or predict a female student's classroom performance..$^{15}$ The difference in ADAT performance we found between male and female applicants warrants further research to understand the reason for this finding.

This study also found a significant difference in ADAT scores between Hispanic and non-Hispanic applicants. Substantial differences were noted between these groups for the ADAT total score as well as for the critical thinking and the data, research interpretation, and evidence-based dentistry section scores. Unfortunately, due to the small number of minority applicants included in the study, we were unable to search for an explanation for this finding. Further evaluation of the ADAT with a larger sample size should be conducted to assess and describe the performance of minority applicants on the ADAT.

Individuals who participated in research scored higher in every section than those with no research experience. The ADAT total score, critical thinking, and biomedical sciences scores were significantly higher for those with research experience. Seymour et al.'s study of the benefits of student research reported that those engaging in research had an "enhancement of understanding of nature and the development of scientific knowledge." ${ }^{18}$ Stewart et al. found that a past research experience was successful in "promoting the acquisition of higher-order inquiry skills that underlie the foundation of critical, scientific thinking." ${ }^{16}$ These critical, scientific thinking skills gained from research experience appeared to be beneficial for the applicants in our study, perhaps helping them to score higher on these aspects of the ADAT.

This study had limitations that must be acknowledged to appropriately evaluate the findings described. The study assessed the academic and demographic characteristics of applicants for a postgraduate residency position at a single academic dental institution, so its results may not be generalizable to applicants of other programs. Our study included 92 of the 460 applicants who took the 2016 ADAT pilot. Ideally, a larger number of the total applicants, applying to multiple institutions, would have been included in this analysis to reduce the possibility of selection bias. A related limitation included the unequal distribution of academic and demographic variables such as TOEFL score, age, and race. The lack of adequate numbers for certain groups or assessment metrics made it impossible to statistically assess the performance of the ADAT for all the desired parameters.

A final limitation surrounds the concept of adequate applicant selection criteria for postgraduate residency programs. The focus of this study was on the potential validity and utility of the ADAT, a numerical assessment instrument. Neither the ADAT nor this study included the assessment of other parameters used for student admission into postgraduate residency programs, such as history of leadership experience or civic engagement. High-stakes exam scores alone are insufficient for evaluating postgraduate applicants, and it is important that residency programs use a broad range of assessment criteria when evaluating potential residents for matriculation.

\section{Conclusion}

This study found several significant correlations between the ADAT and academic metrics historically used to evaluate postgraduate dental residency applicants. Based on the study findings, the ADAT appears to be a useful supplemental assessment instrument, capable of assisting programs with identifying highly qualified residency applicants. Additional independent studies should be conducted to further assess and validate the ADAT. Finally, as program directors continue to decide whether to require applicants to complete the ADAT for admission into their postgraduate program, they should remember that this exam constitutes only one component of an individual's total application and should not be used in isolation for admission decisions. 


\section{Acknowledgments}

The authors greatly appreciate the support and assistance of Dr. Richard Gregory and Ms. Barb Lerner, Office of Graduate Education, Indiana University School of Dentistry, for their contributions to this study.

\section{Disclosure}

Dr. Kelton Stewart served as an ADAT exam construction committee member and has received financial compensation for his efforts in developing the orthodontic component of the ADAT. However, the ADA had no involvement in this study and did not influence the methodology or reported results.

\section{REFERENCES}

1. Brodie AJ, Crow HC, Eber RM, et al. Evaluating postdoctoral dental candidates: assessing the need and recommendations for a national qualifying examination. J Dent Educ 2011;75(6):719-25.

2. American Dental Association. 2010-11 survey of advanced dental education. 2012. At: www.ada.org/ /media/ADA/ Member\%20Center/FIles/survey_advanced_ed.ashx. Accessed 2 Jan. 2017.

3. Ardeshna AP, Fong CA. Characteristics of applicants who obtain interviews at orthodontic postgraduate programs. Angle Orthod 2010;80(2):373-7.

4. Majewski RF, da Fonseca MA, DeVries ES, et al. Factors influencing pediatric dental program directors' selection of residents and demographics of current directors. J Dent Educ 2009;73(3):338-44.

5. Fagin AP, Howell TH, Park SE. Impact of the NBDE grading change on postgraduate admissions processes. J Dent Educ 2015;79(4):362-8.

6. Joint Commission on National Dental Examinations. National Board Dental Examination, part II: 2010 guide. Chicago: American Dental Association, 2010.
7. Neumann LM, MacNeil RL. Revisiting the National Board Dental Examination. J Dent Educ 2007;71(10):1281-92.

8. Willingham WW, Pollack JM, Lewis C. Grades and test scores: accounting for observed differences. J Educ Meas 2002;39:1-37.

9. American Dental Association. The Advanced Dental Admission Test: examinee general information report, 2016 data. At: www.ada.org/ /media/ADA/Education $\% 20$ and\%20Careers/Files/2016_ADAT_Examinee_Information Report.pdf?la=en. Accessed 20 Apr. $201 \overline{8}$.

10. American Dental Association. The Advanced Dental Admission Test (ADAT) program. 2017. At: www.ada. org/ /media/ADA/Education\%20and\%20Careers/Files/ ADAT_DTS_General_Presentation.pdf?la=en. Accessed 2 Feb. 2017.

11. Evans JD. Straightforward statistics for the behavioral sciences. Pacific Grove, CA: Brooks/Cole Publishing, 1996.

12. Cooper HM. Construct validity. In: Handbook of research methods in psychology. Washington, DC: American Psychology Association, 2012:631.

13. Lucas P, Lenstrup M, Prinz J, et al. Language as a barrier to the acquisition of anatomical knowledge. Med Educ 1997;31(2):81-6.

14. Cho Y, Bridgeman B. Relationship of TOEFL iBT scores to academic performance: some evidence from American universities. Lang Testing 2012;29(3):421-42.

15. Kim KH, Zabelina D. Cultural bias in assessment: can creativity assessment help? Interdisc J Crit Pedagogy 2015;6(2):129-47.

16. Stewart CM, Bates RE Jr, Smith GE, Young L. Impact of gender on dental state licensure examination performance. J Dent Educ 2006;70(5):525-30.

17. Fields HW, Fields AM, Beck FM. The impact of gender on high-stakes dental evaluation. J Dent Educ 2003; 67(6):654-60.

18. Seymour E, Hunter AB, Laursen SL, DeAntoni T. Establishing the benefits of research experiences for undergraduates in the sciences: first findings from a three-year study. Sci Educ 2004;88:493-534. 